\title{
N-Cadherin Regulates GluA1-Mediated Depressive-Like Behavior in Adolescent Female Rat Offspring following Prenatal Stress
}

\author{
Shuya Shao ${ }^{a}$ Dan $\mathrm{Yao}^{a}$ Senya $\mathrm{Li}^{\mathrm{b}}$ Jing $\mathrm{Li}^{\mathrm{a}}$ Yufang $\mathrm{Si}^{\mathrm{c}}$ Huiping Zhang ${ }^{\mathrm{b}}$ \\ Zhongliang Zhu ${ }^{\mathrm{c}}$ Dongli Song ${ }^{\mathrm{d}} \mathrm{Hui} \mathrm{Li}^{\mathrm{a}}$

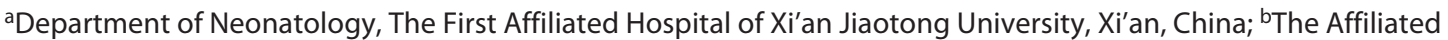 \\ Children Hospital of Xi'an Jiaotong University, Xi'an, China; 'Key Laboratory of Resource Biology and Biotechnology \\ in Western China, Maternal and Infant Health Research Institute and Medical College, Northwestern University, Xi'an, \\ China; dDivision of Neonatology, Department of Pediatrics, Santa Clara Valley Medical Center, San Jose, CA, USA
}

\section{Keywords}

Adolescent depression - Gender difference - Prenatal stress . $\mathrm{N}$-Cadherin · a-Amino-3-hydroxy-5-methyl-4-isoxazole propionic acid receptors

\begin{abstract}
Background: The incidence of depression is twice higher in women than in men, and gender differences in the prevalence rates first emerge around puberty. Prenatal stress (PS) induces gender-dependent depressive-like behavior in adolescent offspring, but the neuro-physiological mechanisms remain unclear. Our study aimed to investigate the possible neuro-physiological mechanisms of gender-dependent depressive-like behavior in PS adolescent offspring and further explored the possibility of treating depression in adolescent female rats. Methods: The pregnant rats were exposed to restraint stress in the third trimester for 7 days. The depressive-like behavior and the expression of $\mathrm{N}$-cadherin and AMPARs in the hippocampus of adolescent offspring rats were assessed. $10 \mathrm{mg} / \mathrm{kg}$ AMPAR antagonist CNQX and $10 \mathrm{mg} / \mathrm{kg}$ $\mathrm{N}$-cadherin antagonist $\mathrm{ADH}-1$ were intraperitoneally injected into female adolescent offspring, respectively; $0.2 \mu \mathrm{g} \mathrm{AM}$ -
\end{abstract}

karger@karger.com www.karger.com/nen

Karger"

BOPEN ACCESS
(C) 2021 The Author(s)

Published by S. Karger AG, Basel

This is an Open Access article licensed under the Creative Commons Attribution-NonCommercial-4.0 International License (CC BY-NC) (http://www.karger.com/Services/OpenAccessLicense), applicable to the online version of the article only. Usage and distribution for commercial purposes requires written permission.
PAR agonist CX546 was administered to the dentate gyrus of male adolescent offspring to determine the role of $\mathrm{N}$-cadherin-AMPARs in depressive-like behavior of the offspring following PS. Results: We found that PS increased N-cadherin expression, which upregulated GluA1 expression in the dentate gyrus, mediating depressive-like behavior in adolescent female rat offspring by reducing PSD-95. In addition, ADH-1 and CNQX improved depressive-like behavior in adolescent female offspring following PS. Furthermore, injection of the CX546 into the dentate gyrus induced depressive-like behavior in PS male offspring. Conclusion: The gender-dependent expression of N-cadherin-GluA1 pathway in adolescent offspring in the dentate gyrus was the key factor in gender differences of depressive-like behavior following PS.

(c) 2021 The Author(s).

Published by S. Karger AG, Basel

\section{Introduction}

Major depression disorder is the most common neuropsychiatric disease and currently affects 350 million people worldwide [1]. Epidemiological investigation re- 
vealed that the incidence of depression is twice higher in women than in men, and gender differences in the prevalence rates first emerge around puberty [1]. Studies have shown that the occurrence of adolescent depression in offspring is related to prenatal stress (PS) [2,3], and the occurrence of adolescent depression is gender specific [4]. In addition, sexually dimorphic responses to PS in offspring cause an increased prevalence of internalizing disorders, such as depression, among females [5]. Our previous study also reported that only adolescent female offspring who experienced PS showed depressive-like behavior or decreased learning and memory abilities, while males were resistant $[6,7]$. Nevertheless, the neuro-physiological mechanism of depressive-like behavior in adolescent female rats remains unknown.

Van et al. [8] found that the altered expression of cell adhesion molecules and glutamate receptors in the hippocampus were involved in the gender-specific effects of PS on offspring through genome-wide sequencing analysis. Cadherin is a transmembrane cell adhesion molecule that allows cells to tightly bind to each other $[9,10]$. There are many types of cadherin, among which $\mathrm{N}$-cadherin is distributed in neurons. $\mathrm{N}$-cadherin plays an important role in nerve migration and localization during brain development [11] and is highly expressed in the hippocampus [12], where it regulates $\alpha$-amino-3-hydroxy-5methyl-4-isoxazole propionic acid receptor (AMPAR)mediated synaptic plasticity.

The AMPARs are important ionic glutamate receptors, consisting of 4 subunits, including GluA1, GluA2, GluA3, and GluA4. AMPARs are widely distributed in the central nervous system, including in the hippocampus [13]. When long-term potentiation occurs in the hippocampus, the distribution of $\mathrm{N}$-cadherin in the synaptic membrane increases [14], the synapse becomes more stable $[15,16]$, and AMPARs in the synaptic membrane are more stable [17]. In the case of long-term depression, Ncadherin is internalized from the synaptic membrane, and then, AMPARs are removed from the postsynaptic membrane [18]. The interaction among $\mathrm{N}$-cadherin and GluA1 and GluA2 promotes the growth of dendritic spines [19].

Although the role of $\mathrm{N}$-cadherin in depression is not clear, emerging evidence has found that AMPAR-mediated synaptic plasticity is critical in the pathogenesis of stress-related depression [20-22]. PSD-95 is an important marker of synaptic plasticity [23] that is decreased in the hippocampus of male rats following stress [24]. Male mice susceptible to chronic stress exhibit depressive-like behavior correlated with down-regulated expression of
GluA1 and GluA2, which upregulates expression of postsynaptic PSD-95 [25]. However, these studies only included adult male subjects; it is unclear whether N-cadherin-AMPARs mediate depressive-like behaviors in adolescent female rats by regulating PSD-95.

Our previous study found that adolescent female offspring who experienced PS showed depressive-like behavior, while males were resistant [6] and offspring exposed to PS exhibit gender-dependent alterations in dendrite length and fulcrum in the hippocampus [26]. In addition, some studies have investigated the effects of AMPARs on depressive-like behavior in the hippocampus after PS exposure, most of which only included male subjects [2729]. However, whether $\mathrm{N}$-cadherin regulates the AMPAR-dependent synaptic plasticity-mediated depressivelike behavior in adolescent female offspring following PS remains unclear. Therefore, our study aimed to investigate the role of $\mathrm{N}$-cadherin-AMPAR pathway in mediating gender-dependent depressive-like behavior in PS adolescent offspring and further explored the possibility of treating depression in adolescent female rat offspring.

\section{Materials and Methods}

\section{Animals}

Sprague-Dawley rats were housed in an environment with controlled temperature $\left(22 \pm 1^{\circ} \mathrm{C}\right)$, humidity $(60 \%)$, and 12-h light/12$\mathrm{h}$ dark cycles with free access to food and water. The lights were turned on at 8:00 a.m. and turned off at 8:00 p.m. Every effort was made to optimize comfort and to minimize the use of animals. All the experimental procedures were performed according to the institutional guidelines of the Animals Care and Use Committee of Xi'an Jiaotong University and were approved by Xi'an Jiaotong University Health Science Center.

\section{Prenatal Stress}

Nulliparous female rats (250-270 g) were housed with male rats $(280-350 \mathrm{~g})$ for mating (3:1), and the vaginal smear was examined the following morning. The day on which the vaginal smear was positive was defined as day 0 of gestation. Each pregnant rat was subsequently housed individually. All the pregnant rats were randomly assigned to either the control group $(n=8)$ or the PS group $(n=8)$. The PS pregnant rats were subjected to restraint stress 3 times per day (at approximately 08:00-11:00, 12:00-15:00, and 16:00-19:00), for 45 min per session on gestational days 14-20 [30-32]. The pregnant dams returned into their home cages between each session of restraint, and the rats did not have water and food available for the whole period of stress, which were free access to food and water for the rest of the time. The rats in the control group have water and food available for the whole period of investigation. The device was a transparent cylinder $(6.8 \mathrm{~cm}$ in diameter) with an adjustable length to accommodate the size of the animals. Air holes in the cylinder were for breathing. The control group pregnant rats were undisturbed. 
The birth of offspring was considered postnatal day 0. After birth, the offspring were left undisturbed with their mothers until weaning (21 days after birth). After weaning, male and female offspring were housed separately, and each sex offspring from 1 litter was housed in a cage. For the first experiment, offspring rats were assigned to the CON (male, $n=13$; female, $n=15$ ) or PS (male, $n=16$; female, $n=16$ ) group for further behavioral experiments. Only litters of 6-12 pups were included in this study, and 5-weekold offspring ( 2 pups per sex from each litter at most to avoid a "litter effect") were used $[6,33]$.

\section{Drugs}

The AMPA receptor antagonist CNQX, the selective AMPAR agonist CX546, and the $\mathrm{N}$-cadherin antagonist $\mathrm{ADH}-1$ were obtained from Sigma-Aldrich, St. Louis, MI, USA. CNQX and ADH1 were dissolved in $0.9 \%$ saline solution, and CX546 was dissolved in $1 \%$ DMSO, $1 \%$ ethanol, and $98 \%$ saline. The rats were intraperitoneally injected with CNQX or ADH-1 (10 mg/kg) or an equal volume of saline and were subjected to sucrose preference test (SPT) $0.5 \mathrm{~h}$ after administration $[34,35]$. The CX546 doses used were the same as previously reported [36], and drugs or the same volume of vector (1\% DMSO, $1 \%$ ethanol, and $98 \%$ saline) were microinjected into the hippocampus $30 \mathrm{~min}$ before the SPT.

For the second experiment, female offspring rats were divided into 6 groups and 6 litters were used in each group: CON + saline $(n=6), \mathrm{PS}+$ saline $(n=6), \mathrm{CON}+\mathrm{CNQX}(n=6), \mathrm{PS}+\mathrm{CNQX}(n=$ 6), $\mathrm{CON}+\mathrm{ADH}-1(n=6)$, and PS + ADH-1 $(n=6)$; to avoid a "litter effect," 2 female pups from each litter at most were used in 5-7-weekold offspring. For the third experiment, male offspring rats were divided into 4 groups: CON + vector $(n=6), \mathrm{CON}+\mathrm{CX} 546(n=6)$, PS + vector $(n=6)$, and PS + CX546 $(n=6)$, and at most 2 male pups from each litter were used in 5-week-old offspring.

\section{Microinjection}

A tube was implanted in the dentate gyrus of the hippocampus of rats 5 weeks after birth. Rats were anaesthetized with $10 \%$ ethyl carbamate (0.3-0.4 mL/100 g, i.p.), and their heads were fixed on a 502603 brain stereotaxic device (WPI, USA). According to the Paxinos and Watson [37] rat brain stereopsis map, a stainless steel casing with a core was inserted on each side of the dentate gyrus (AP: $-3.5 \mathrm{~mm}, \mathrm{ML}: \pm 2.1 \mathrm{~mm}$; DV: $-3.7 \mathrm{~mm}$ relative to bregma) and fixed with glass ionomer cement and dental powder. The rats were housed separately after the operation. After 7 days of recovery, microinjection into the dentate gyrus was performed using a single channel microinjection pump (KDS, USA). The CX546 (1 $\mu \mathrm{L} \times 0.1 \mu \mathrm{g} / \mu \mathrm{L}$, Sigma-Aldrich, St. Louis, MI, USA) was slowly injected into both sides of the dentate gyrus at a rate of $0.5 \mu \mathrm{L} / \mathrm{min}$. The needle was kept in position for 5 min after injection to prevent drug efflux. According to different treatments, the rats were classified into 4 categories: CON + vector $(n=6), \mathrm{CON}+\mathrm{CX} 546(n=$ $6)$, PS + vector $(n=6)$, and PS + CX546 $(n=6)$. The following experiments were performed $30 \mathrm{~min}$ after the operation.

\section{Behavioral Test}

Sucrose Preference Test

The SPT was performed 36 days after birth. For the CX546 administration, it was performed 42 days after birth. All the rats were provided with $2 \%(\mathrm{w} / \mathrm{v})$ sucrose solution and water at the same time for 24-h adaptation. At the same time, the total consumption of sucrose and water for $24 \mathrm{~h}$ was recorded. The next day, the rats were subjected to $4 \mathrm{~h}$ of water deprivation before the behavioral test. To prevent the rats from habitually drinking from the water bottles, the daily placement of sucrose and drinking water was alternated. After deprivation, the consumption of sucrose and water of each group was recorded over $2 \mathrm{~h}$. Three SPTs were performed for each rat. Sucrose preference was used as a measure of depressive-like behavior. Sucrose preference $=$ sucrose solution consumption/(drinking water consumption + sucrose solution consumption) $\times 100 \%$.

Forced Swim Test

The forced swim test (FST) was performed 38 days after birth according to previous reports [38]. For the CX546 administration, it was performed 42 days after birth. Briefly, each rat was individually placed into a Perspex cylinder (diameter $18 \mathrm{~cm}$ and height 40 $\mathrm{cm}$ ) filled with $25^{\circ} \mathrm{C}$ water with a height of $30 \mathrm{~cm}$ for $15 \mathrm{~min}$ as pretest under low-light conditions. After $24 \mathrm{~h}$, the procedure was repeated, but on this occasion, the duration that the rats remained immobile and the time of first immobility (latency immobility time) during a 5-min observation period were recorded. Rats spending more immobile time or less immobility latency time than the control group were characterized as increasing depressive-like behavior. The rats were sacrificed the day after FST.

\section{Quantitative Real-Time PCR}

The quantitative real-time PCR was conducted according to previous reports [7]. Offspring rats anesthetized with intraperitoneal chloral hydrate $(0.3-0.4 \mathrm{~mL} / 100 \mathrm{~g}$, i.p. $)$ were decapitated. The hippocampus tissues were dissected and frozen in liquid nitrogen and then kept in $-80^{\circ} \mathrm{C}$ freezer immediately. Total RNA was extracted by RNA fast 200 RNA kit (Xianfeng Biotech, Shaanxi, China), according to the manufacturer's instructions. The cDNA was synthesized using the PrimeScriptTM RT Master Mix Kit (RR036A; TaKaRa, Kyoto, Japan). Quantitative real-time PCR was performed with the SYBR ${ }^{\circledR}$ Premix Ex Taq ${ }^{\mathrm{TM}}$ II (Tli RNaseH Plus) (RR8201, TaKaRa) on Bio-Rad CFX96 system (Bio-Rad, Hercules, CA, USA). The primer sequences are shown in online supplementary Table 1 (see www.karger.com/doi/10.1159/000518383 for all online suppl. materials). Every sample was performed in triplicates. Fold changes in the target gene relative to corresponding GAPDH endogenous control were calculated using the $2^{-\Delta \Delta \mathrm{Ct}}$ method.

\section{Western Blot}

The Western blot was conducted according to previous reports [7]. Total proteins were isolated from the hippocampus with RIPA buffer (Solarbio, China). The protein sample was separated with $10 \%$ SDS-PAGE and then transferred to a PVDF film (Millipore, USA). After blocking with $5 \%$ skim milk at room temperature for $2 \mathrm{~h}$, primary antibodies of GluA1 (1:5,000, ab31232), GluA2 (1:5,000, ab20673), GluA3 (1:5,000, ab40845), GluA4 (1:5,000, ab115322), N-cadherin (1:5,000, ab18203), PSD-95(1:5,000, ab18258), and $\beta$-actin (1:2,000, ab8227) obtained from Abcam (USA) were added and incubated at $4^{\circ} \mathrm{C}$ overnight. After washing, goat anti-rabbit secondary antibody $(1: 5,000$, Pioneer, China) was added and incubated at room temperature for $2 \mathrm{~h}$. Then, the film was developed with ECL chemiluminescence (Millipore, China) and analyzed by imaging system (Bio-Rad, USA). The gray values of the target protein bands were scanned by Quantity One software. Results were standardized to $\beta$-actin. 
Immunofluorescence

After the behavioral test, the rats were euthanized and transcardially perfused with $0.9 \% \mathrm{NaCl}$. Half of the brain was removed and fixed in $4 \%$ paraformaldehyde for $24 \mathrm{~h}$ at $4^{\circ} \mathrm{C}$ and immersed in $15 \%, 20 \%$, and $30 \%$ sucrose concentrations overnight. Serial sections $(10 \mu \mathrm{m} / \mathrm{section})$ were cut through the entire anteroposterior extension of the hippocampus using a freezing microtome. The sections were permeabilized in $0.3 \%$ Triton $\mathrm{X}-100$ for $30 \mathrm{~min}$ and then blocked in $10 \%$ normal goat serum for $1 \mathrm{~h}$ at $37^{\circ} \mathrm{C}$ before overnight incubation in primary antibodies against $\mathrm{N}$-cadherin (PA5-19486, Invitrogen) and GluA1 (\#13185, CST). Subsequently, the samples were incubated in secondary antibodies for an additional $2 \mathrm{~h}$ for fluorescence detection and covered with a cover slip. Images were acquired using a fluorescence microscope (Nikon Eclipse Ti).

\section{Statistical Analysis}

SPSS PASW Statistics v22.0 was used for data analysis. All data were represented as mean \pm standard error of measurement. For data with variance homogeneity and normal distribution, the 2-way ANOVA was performed. After the influencing factor was determined, the one-way ANOVA-stratified analysis was used. Mean differences with $>2$ groups were compared using one-way ANOVA, followed by Fisher's LSD test to multiple comparisons if the main effect was significant at $p<0.05$. A $p<0.05$ was considered statistically significant.

\section{Results}

\section{Adolescent Female Offspring Exhibited Depressive- \\ Like Behavior following PS}

After exposure to 7 days of restraint stress during the third trimester of pregnancy, the depressive-like behavior of the offspring was tested 5-6 weeks after birth [39] (shown in Fig. 1a). Based on the 2-way ANOVA, the overall interaction (sex $\times$ PS) for sucrose consumption was observed $\left(F_{[1,57]}=8.652, p=0.005\right)$. The results showed that the sucrose consumption in the females of PS group decreased $23.80 \%$ compared to that in the CON group $\left(F_{[1,30]}=6.901, p=0.013\right)$. However, there was no significant change in male offspring in sucrose consumption (shown in Fig. 1c). Both sex and PS had no effect on total water consumption of the offspring rats (shown in Fig. 1b). In the CON group, gender had no effect on sucrose consumption.

In FST, the overall interaction ( $\mathrm{sex} \times \mathrm{PS})$ was observed $\left(F_{[1,57]}=9.288, p=0.003\right)$ for the immobility time $\left(F_{[1,57]}\right.$ $=9.288, p=0.003)$ and the latent immobility time $\left(F_{[1,57]}\right.$ $=11.769, p=0.001)$. The immobility time of the females in the PS group, but not the males, was significantly longer than that in the CON group $\left(F_{[1,30]}=18.052, p<0.001\right.$, shown in Figure 1e). In addition, the latent immobility time was reduced in the PS female offspring $\left(F_{[1,30]}=\right.$
$26.255, p<0.001$ ) but not in the PS male offspring (shown in Fig. 1f). In the CON group, gender did not affect the immobility time and latent immobility time in FST. Moreover, PS had no effect on the baseline activity (shown in Fig. 1d). In general, adolescent female offspring exhibited depressive-like behavior following PS, while male offspring were resistant.

\section{PS Upregulated N-Cadherin and GluA1 in the Hippocampus}

To explore the impacts of PS on the expression of $\mathrm{N}$ cadherin in adolescent offspring, we performed an analysis of $\mathrm{N}$-cadherin expression in the hippocampus (shown in Fig. 2a). Based on the 2-way ANOVA, we observed the overall interaction (sex $\times$ PS) for both the relative expressions of N-cadherin mRNA $\left(F_{[1,20]}=13.512, p=0.001\right)$ and protein $\left(F_{[1,20]}=4.638, p=0.044\right)$. The one-way ANOVA-stratified analysis showed that PS increased Ncadherin expression in the hippocampus of the female offspring (N-cadherin mRNA, $F_{[1,10]}=22.389, p=0.001$; $\mathrm{N}$-cadherin protein, $F_{[1,10]}=6.643, p=0.028$, shown in Figure $2 b, e)$. However, there was no significant change in the expression of $\mathrm{N}$-cadherin in the male offspring. This finding suggested that $\mathrm{N}$-cadherin probably mediated a gender-specific behavioral phenotype in adolescent offspring after PS.

With respect to the N-cadherin-regulated expression of AMPARs, we next explored whether AMPAR isozymes in the hippocampus are required for depressive-like behavior following PS. Based on the 2-way ANOVA, the overall interaction (sex $\times$ PS) was observed for both the relative expression of GluA1 mRNA $\left(F_{[1,20]}=12.583, p=0.002\right)$ and protein $\left(F_{[1,20]}=7.236\right.$, $p=0.014)$ and the relative expression of GluA2 mRNA $\left(F_{[1,20]}=15.051, p=0.001\right)$ and protein $\left(F_{[1,20]}=5.974\right.$, $p=0.024)$. The one-way ANOVA-stratified analysis showed that the PS female offspring exhibited increased GluA1 and GluA2 mRNA expression (GluA1, $F_{[1,10]}=$ 30.484, $p<0.001$; GluA2, $F_{[1,10]}=19.419, p=0.001$, shown in Figure $2 \mathrm{c}, \mathrm{d}$ ) and protein expression (GluA1, $F_{[1,10]}=5.039, p=0.049$; GluA2, $F_{[1,10]}=5.951, p=$ 0.035 , shown in Fig. $2 \mathrm{f}, \mathrm{g}$ ) in the hippocampus compared to the CON females, while no significant differences were observed in the PS male offspring for the 4 tested isoforms. PS did not exert significant effects on either the GluA3 or GluA4 expression in the hippocampus (see online suppl. material 1).

We also found that PS increased $\mathrm{N}$-cadherin and GluA1 expression in the entire hippocampus of the female offspring by immunofluorescence (online suppl. 


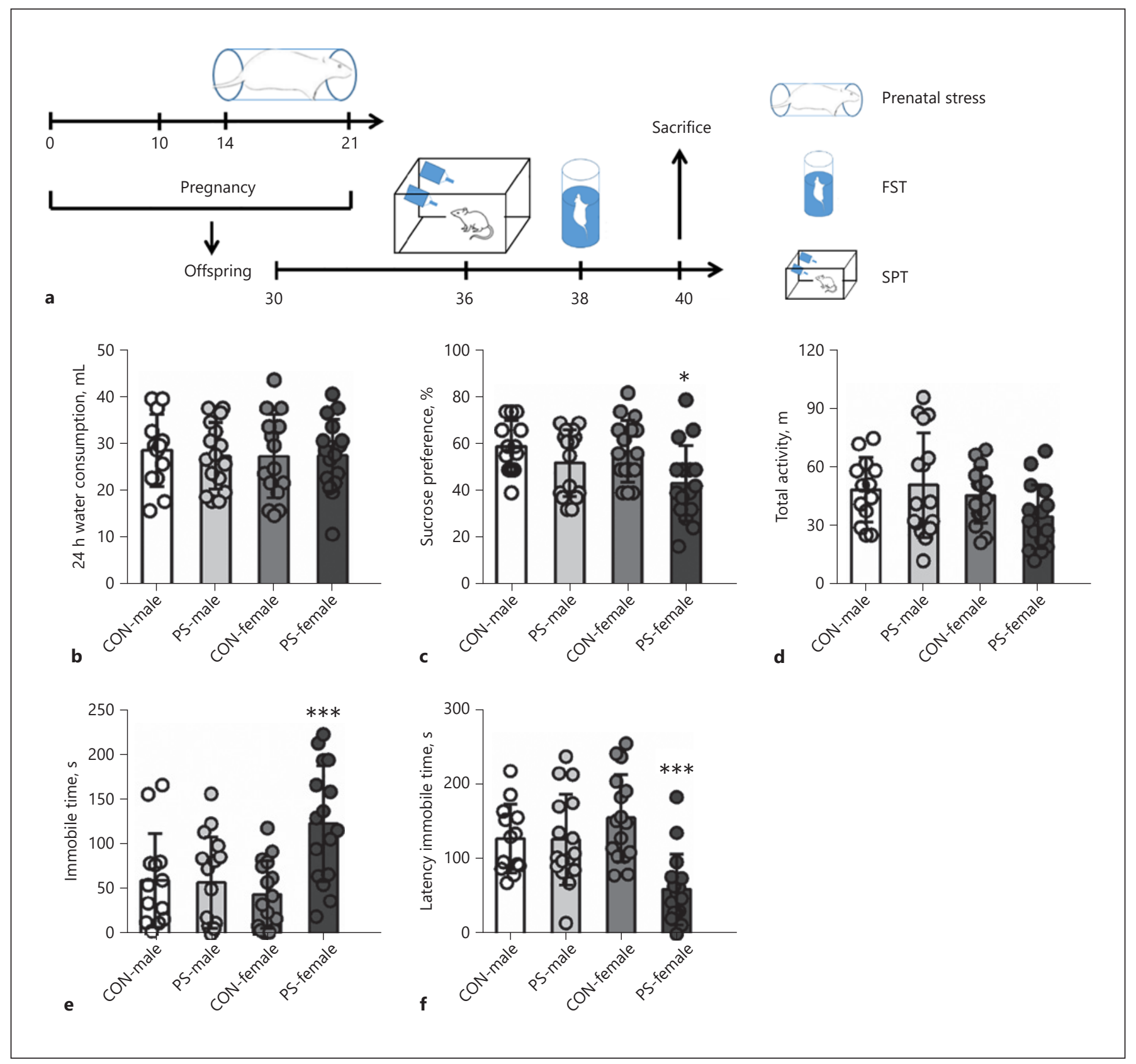

Fig. 1. Effects of PS on the behavior of rat offspring. The SPT and FST were used to study depressive-like behavior of offspring rats. a Study design of PS model establishment and behavioral test. b 24-h water consumption in the SPT. c Sucrose preference. d To- tal activity in the FST. e Immobility time in the FST. $\mathbf{f}$ Latent immobility time in the FST. ${ }^{*} p<0.05$ versus CON-female, ${ }^{* * *} p<$ 0.001 versus CON-female. PS, prenatal stress; SPT, sucrose preference test; FST, forced swim test. material 2). Furthermore, the upregulation of N-cadherin and GluA1 in the PS group was more obvious in dentate gyrus and N-cadherin and GluA1 were co-localized $\left(F_{[1}\right.$, ${ }_{10]}=8.163, p=0.046 ; F_{[1,10]}=23.352, p=0.008$, shown in Figure $2 \mathrm{~h}$ ). Therefore, these results suggested that the de- pressive-like behavior in female adolescent offspring exposed to PS may be mainly caused by the increased expression of $\mathrm{N}$-cadherin-GluA1 pathway in the dentate gyrus. 


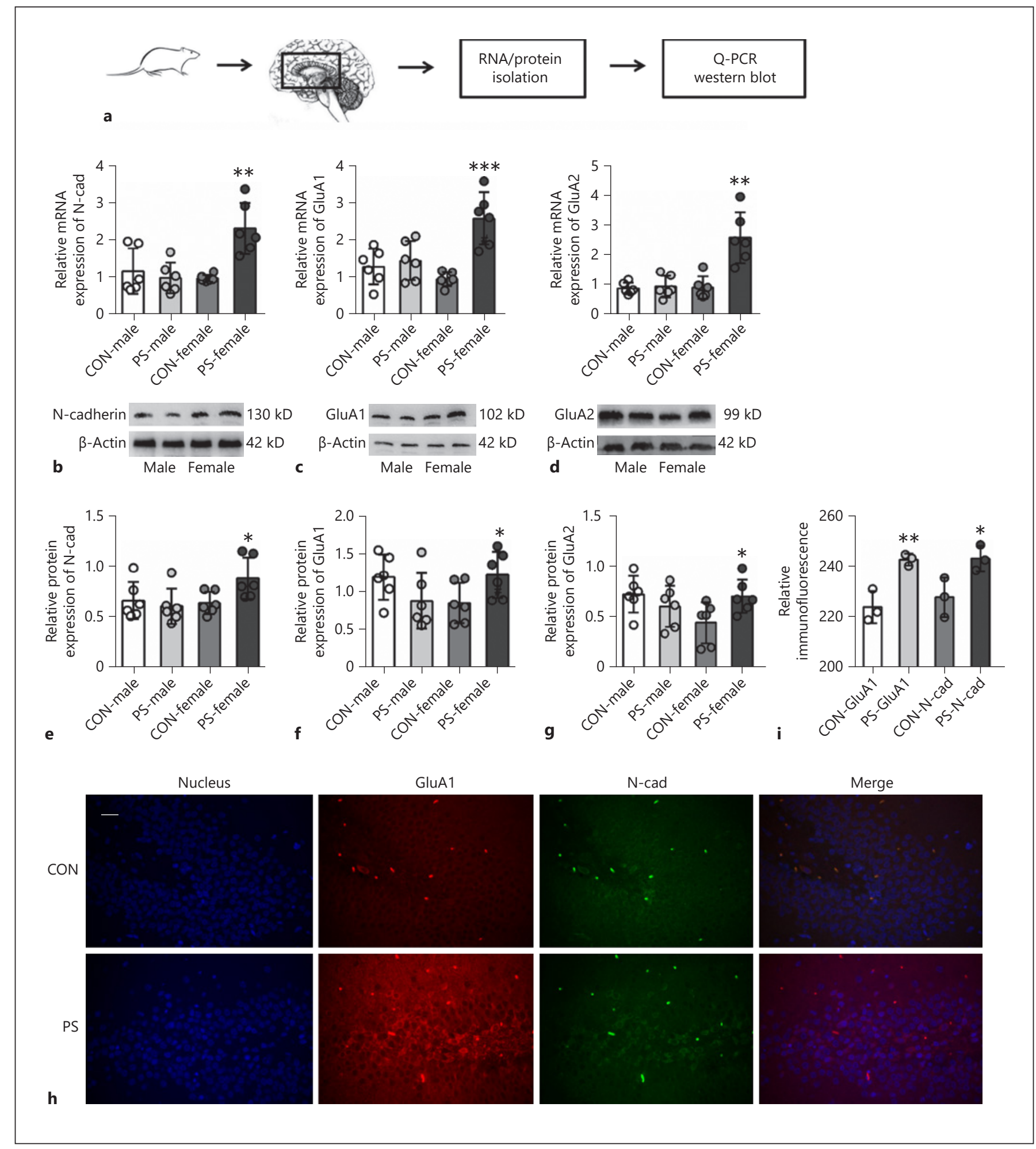

Fig. 2. Effects of PS on the expression of N-cadherin and GluA1-2 in rat offspring. a Experimental protocol. b-d Relative mRNA expression of N-cadherin and GluA1-2 in the hippocampus. e-g Protein expression of N-cadherin and GluA1-2 in the hippocampus. $\mathbf{h}$ Representative images of immunofluorescence staining showing $\mathrm{N}$-cadherin and GluA1 in the dentate gyrus. $N=6$ rats/ group, and the number of experiments $=3$. Magnification $\times 40$. Scale bar, $50 \mu \mathrm{m}$. i Immunofluorescence intensity analysis. ${ }^{*} p<$ 0.05 versus CON-female, ${ }^{* *} p<0.01$ versus CON-female, ${ }^{* *} p<$ 0.001 versus $\mathrm{CON}$-female. PS, prenatal stress. 


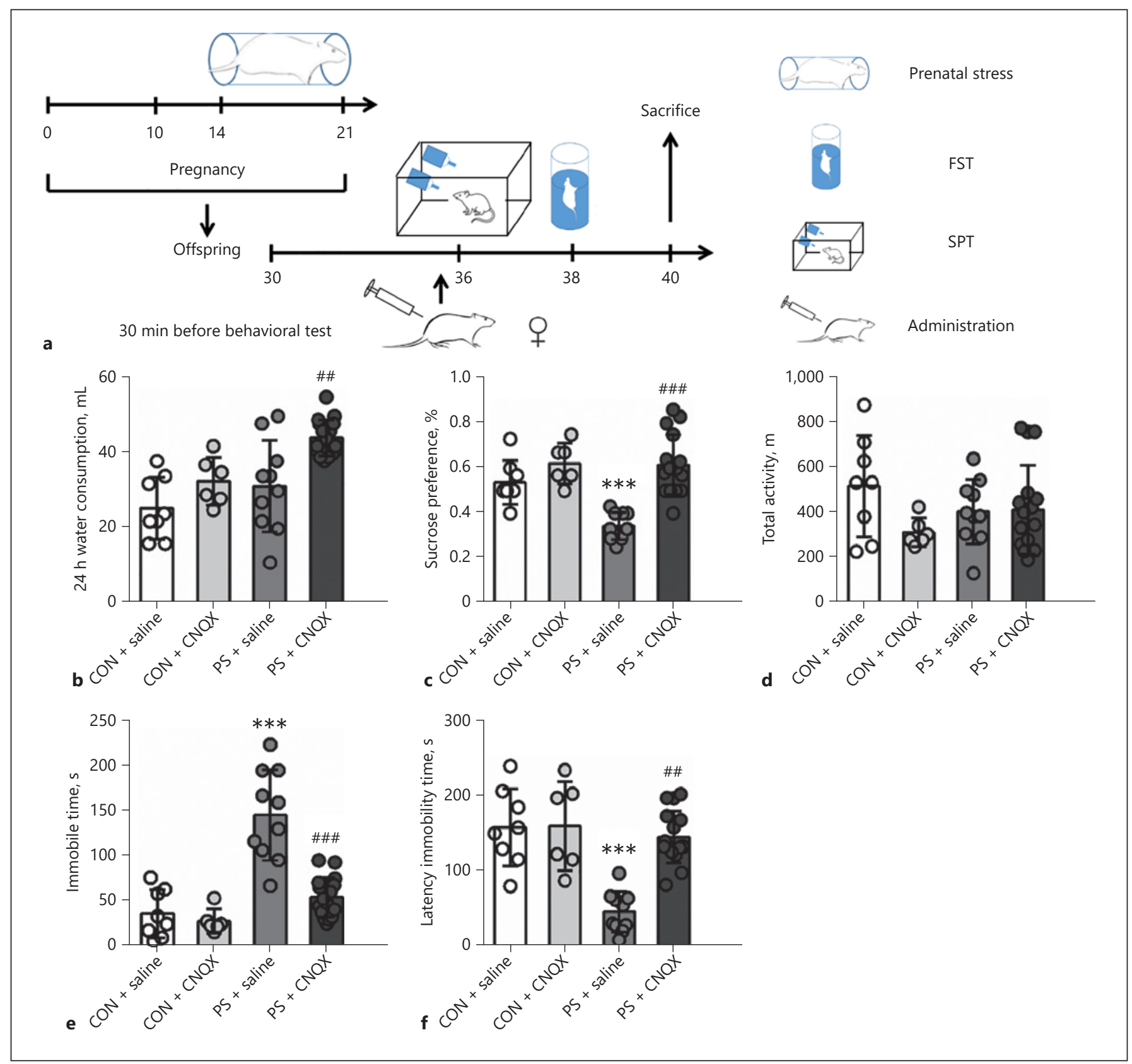

Fig. 3. Effects of the AMPAR receptor antagonist CNQX on the behavior of female rat offspring. a Experimental protocol. b Study design of PS model establishment, CNQX administration, and behavioral test. c Sucrose preference. d Total activity in the FST. e Immobility time in the FST. $\mathbf{f}$ Latent immobility time in the FST. ${ }^{* * *} p<0.001$ versus CON + saline, ${ }^{\# \#} p<0.01$ versus PS + saline, $\# \# p<0.001$ versus PS + saline. PS, prenatal stress; FST, forced swim test; SPT, sucrose preference test.
AMPAR Antagonist CNQX Improved Depressive-Like Behavior in Adolescent Female Offspring after PS

To confirm that GluA1 is required for the depressivelike behavior in adolescent female offspring exposed to PS conditions, we injected the AMPAR antagonist CNQX into PS female offspring 30 min before behavioral testing (shown in Fig. 3a). Based on the 2-way ANOVA, the overall interaction $(\mathrm{CNQX} \times \mathrm{PS})$ for sucrose consumption was observed $\left(F_{[1,40]}=6.962, p=0.012\right)$, as well as the effect of PS $\left(F_{[1,40]}=7.721, p=0.009\right)$. The CNQX admin- 
Fig. 4. Effects of the AMPAR antagonist CNQX on $\mathrm{N}$-cadherin expression in female rat offspring. a, b Relative mRNA expression and protein expression of GluA1-2 in the hippocampus. c, d Relative mRNA expression and protein expression of $\mathrm{N}$-cadherin in the hippocampus. ${ }^{* *} p<0.01$ versus $\mathrm{CON}+$ saline, ${ }^{* * *} p<0.001$ versus $\mathrm{CON}$ + saline, ${ }^{\# \#} p<0.001$ versus PS + saline. AMPARs, a-amino-3-hydroxy-5-methyl4-isoxazole propionic acid receptors; PS, prenatal stress.
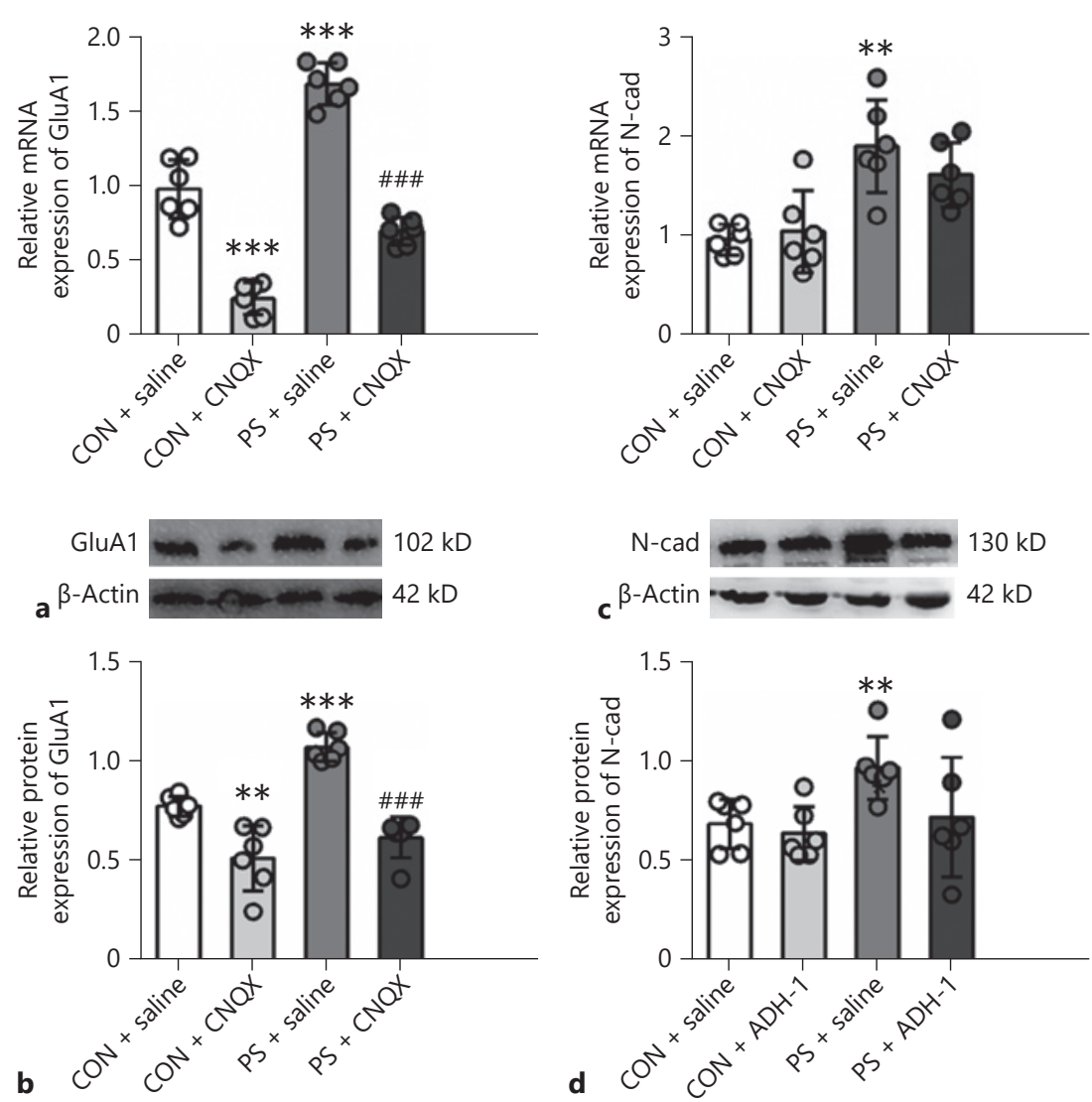

istration had no effect on the behavior of offspring in the control group. However, we found that CNQX significantly improved the depressive-like behavior of adolescent female offspring after PS, as evidenced by the fact that the sucrose consumption of the females in the PS group significantly increased $78.55 \%$ after injection of CNQX $\left(F_{[1,24]}=36.839, p<0.001\right.$, shown in Figure 3c). Both CNQX and PS had no effect on the total water consumption (shown in Fig. 3b). Furthermore, the overall interaction $(\mathrm{CNQX} \times \mathrm{PS})$ for both immobility time and latent immobility time was observed $\left(F_{[1,40]}=15.122, p<\right.$ $\left.0.001 ; F_{[1,40]}=5.379, p=0.026\right)$, as well as the effect of PS $\left(F_{[1,40]}=40.820, p<0.001 ; F_{[1,40]}=4.735, p=0.036\right)$. The one-way ANOVA-stratified analysis showed that the immobility time decreased 65.55\% $\left(F_{[1,24]}=40.656, p<\right.$ 0.001 , shown in Figure $3 e$ ), while latent immobility time increased $207.65 \%\left(F_{[1,24]}=13.067, p=0.001\right.$, shown in Figure 3f) in the PS female offspring after CNQX injection.

We also found the interaction of CNQX and PS on the relative mRNA and protein expression of GluA1 $\left(F_{[1,20]}\right.$ $\left.=4.886, p=0.039 ; F_{[1,20]}=4.965, p=0.037\right)$, as well as the effect of PS $\left(F_{[1,20]}=103.787, p<0.001 ; F_{[1,20]}=21.284\right.$, $p<0.001)$ and CNQX administration $\left(F_{[1,20]}=229.398\right.$, $\left.p<0.001 ; F_{[1,20]}=68.317, p<0.001\right)$. CNQX administration reduced GluAl expression in the hippocampus of CON group (GluA1 mRNA, $F_{[1,10]}=65.223, p<0.001$; GluA1 protein, $t=2.617$, $\mathrm{df}=10, p=0.026$, shown in Fig. $4 a, b)$. In addition, PS significantly increased GluA1 in the hippocampus (GluA1 mRNA, $F_{[1,10]}=51.615, p<$ 0.001; GluA1 protein, $F_{[1,10]}=67.070, p<0.001$, shown in Figure 4a, b), which was rescued by CNQX administration (GluA1 mRNA, $F_{[1,10]}=209.991, p<0.001$; GluA1 protein, $F_{[1,10]}=79.247, p<0.001$, shown in Fig. $4 \mathrm{a}$, b). However, CNQX had no effect on $\mathrm{N}$-cadherin expression in the hippocampus of CON and PS group (shown in Fig. 4c, d). This further demonstrated that GluA1 in the hippocampus was required for depressive-like behavior in female offspring exposed to PS, but altered expression of GluA1 in the hippocampus had no effect on N-cadherin. 


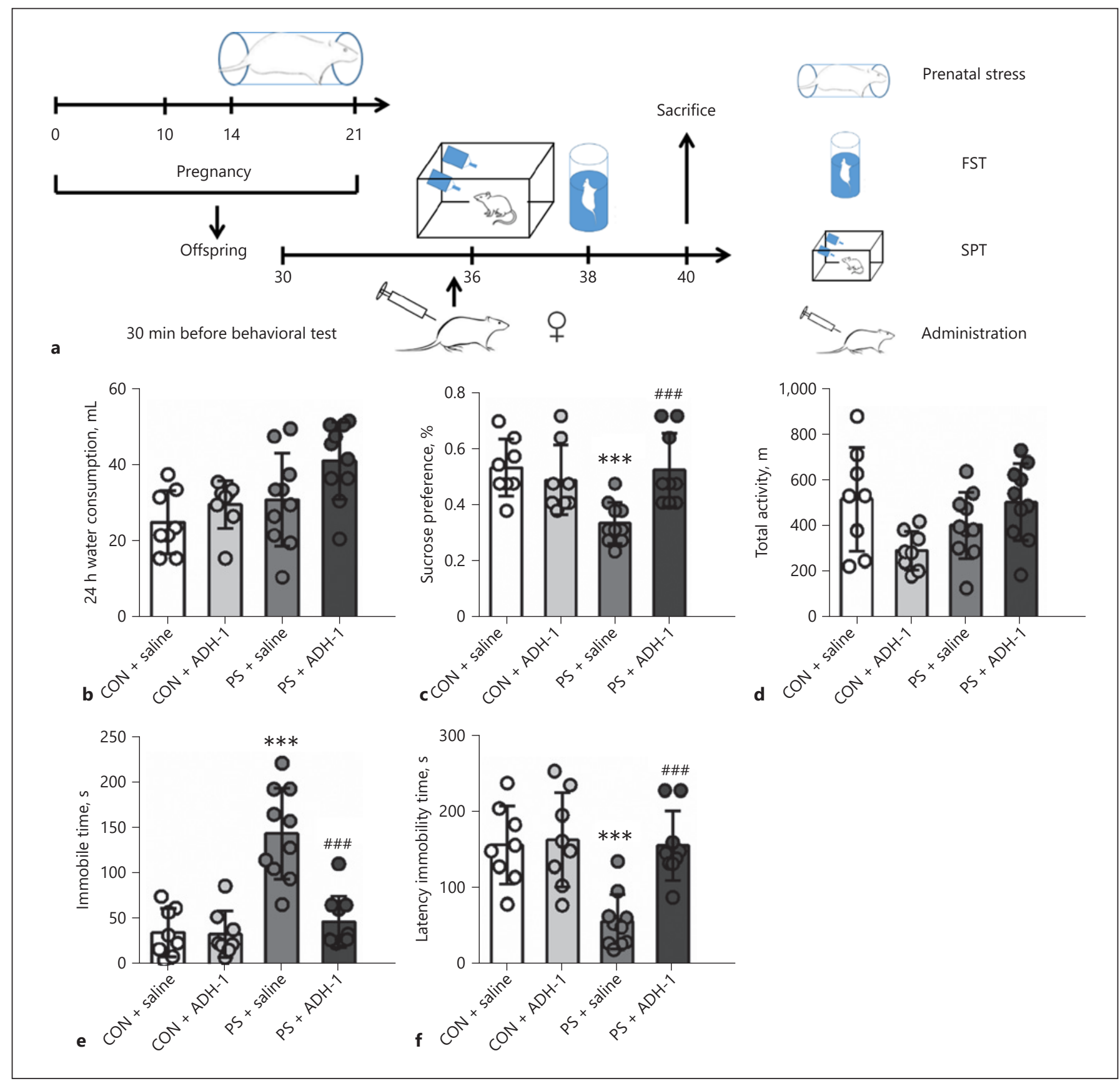

Fig. 5. Effects of the N-cadherin antagonist ADH-1 on the behavior of female rat offspring. a Study design of PS model establishment, ADH-1 administration, and behavioral test. b 24-h water consumption in the SPT. c Sucrose preference. d Total activity in

\section{$N$-Cadherin Antagonist ADH-1 Improved the}

Depressive-Like Behavior of Adolescent Female

Offspring by Regulating the Levels of GluA1 after PS

To confirm that $\mathrm{N}$-cadherin regulates the depressivelike behavior of adolescent female offspring under PS the FST. e Immobility time in the FST. $\mathbf{f}$ Latent immobility time in the FST. ${ }^{* * *} p<0.001$ versus CON + saline, ${ }^{\# \#} p<0.01$ versus PS + saline, ${ }^{\# \# \#} p<0.001$ versus PS + saline. PS, prenatal stress; SPT, sucrose preference test; FST, forced swim test. 
Fig. 6. Effects of the $\mathrm{N}$-cadherin antagonist ADH-1 on GluA1 and GluA2 expression of female rat offspring. a Relative mRNA expression of $\mathrm{N}$-cadherin in the hippocampus. $\mathbf{b}$ Protein expression of $\mathrm{N}$-cadherin in the hippocampus. c Relative mRNA expression of GluA1-2 in the hippocampus. d Protein expression of GluA1-2 in the hippocampus. ${ }^{*} p<0.05$ versus $\mathrm{CON}+$ saline, ${ }^{* *} p<0.01$ versus CON + saline, ${ }^{* * *} p<$ 0.001 versus $\mathrm{CON}+$ saline, ${ }^{\# \#} p<0.01$ versus $\mathrm{PS}+$ saline, ${ }^{\# \#} p<0.001$ versus $\mathrm{PS}+\mathrm{sa}$ line.

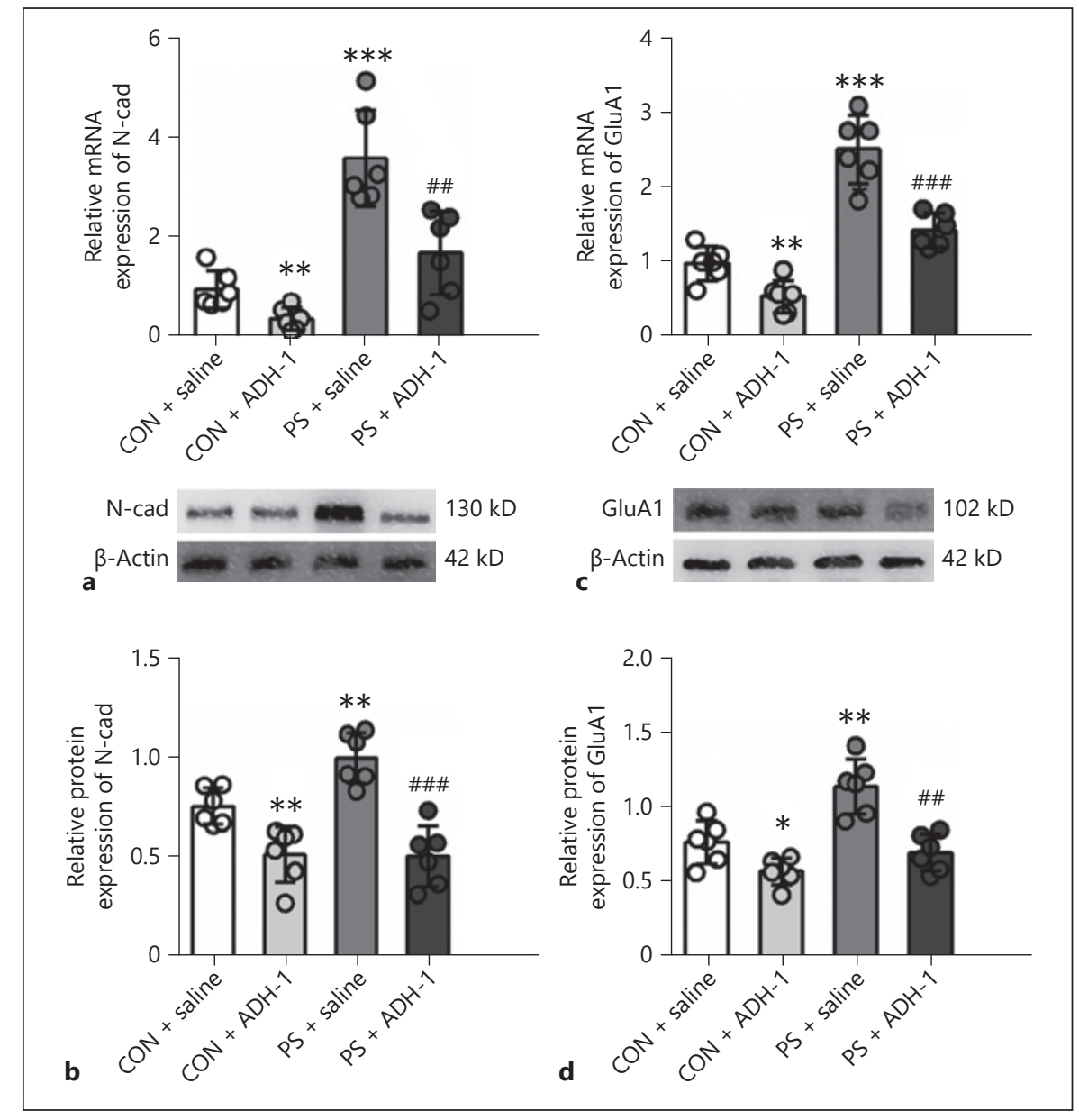

the effect of PS $\left(F_{[1,35]}=3.456, p=0.037\right)$. We found PSinduced depressive-like behavior in female offspring (shown in Fig. 5cf). In addition, the ADH-1 significantly improved depressive-like behavior in the adolescent female offspring after PS, while had no effect on the behavior of offspring in the control group. After injecting $\mathrm{ADH}-1$, the sucrose consumption by the female offspring in the PS group increased $55.01 \%\left(F_{[1,17]}=15.517, p=\right.$ 0.001 , shown in Figure $5 \mathrm{c})$. Furthermore, the overall interaction $(\mathrm{ADH}-1 \times \mathrm{PS})$ for both immobility time and latent immobility time was observed $\left(F_{[1,35]}=16.457, p<\right.$ $\left.0.001 ; F_{[1,35]}=7.979, p=0.008\right)$, as well as the effect of PS $\left(F_{[1,35]}=24.919, p<0.001 ; F_{[1,35]}=10.582, p=0.003\right)$. The one-way ANOVA-stratified analysis showed that the immobility time decreased $68.15 \%\left(F_{[1,17]}=26.842, p<\right.$ 0.001 , shown in Figure $5 \mathrm{e}$ ), and the latent immobility time increased $171.07 \%\left(F_{[1,17]}=54.780, p<0.001\right.$, shown in Figure $5 f$ ) in the PS female offspring after $\mathrm{ADH}-1$ injection.
We analyzed whether intraperitoneal ADH-1 improved depressive-like behavior in female offspring after PS by regulating GluA1. Based on the 2-way ANOVA, the interaction $(\mathrm{ADH}-1 \times \mathrm{PS})$ on the relative $\mathrm{mRNA}$ and protein expression of N-cadherin $\left(F_{[1,20]}=5.665, p=0.027 ; F_{[1,20]}=\right.$ $5.559, p=0.029)$ were observed, as well as the effect of PS $\left(F_{[1,20]}=51.228, p<0.001 ; F_{[1,20]}=4.762, p=0.041\right)$ and ADH-1 administration $\left(F_{[1,20]}=20.454, p<0.001 ; F_{[1,20]}=\right.$ 47.937, $p<0.001)$. We found that ADH-1 administration reduced $\mathrm{N}$-cadherin expression in the hippocampus of CON group (N-cadherin mRNA, $F_{[1,20]}=10.996, p=0.008$; $\mathrm{N}$-cadherin protein, $F_{[1,20]}=12,627, p=0.005$, shown in Fig. 6a, b). Moreover, ADH-1 rescued the upregulated Ncadherin expression in hippocampus induced by PS (N-cad mRNA, $F_{[1,20]}=13.300, p=0.004 ; \mathrm{N}$-cad protein, $F_{[1,20]}=$ $36.672, p<0.001$; shown in Figure 6a, b).

The interaction $(\mathrm{ADH}-1 \times \mathrm{PS})$ on the relative mRNA and protein expression of GluA1 $\left(F_{[1,20]}=6.987, p=\right.$ $\left.0.016 ; F_{[1,20]}=4.867, p=0.039\right)$ were also observed, as well 

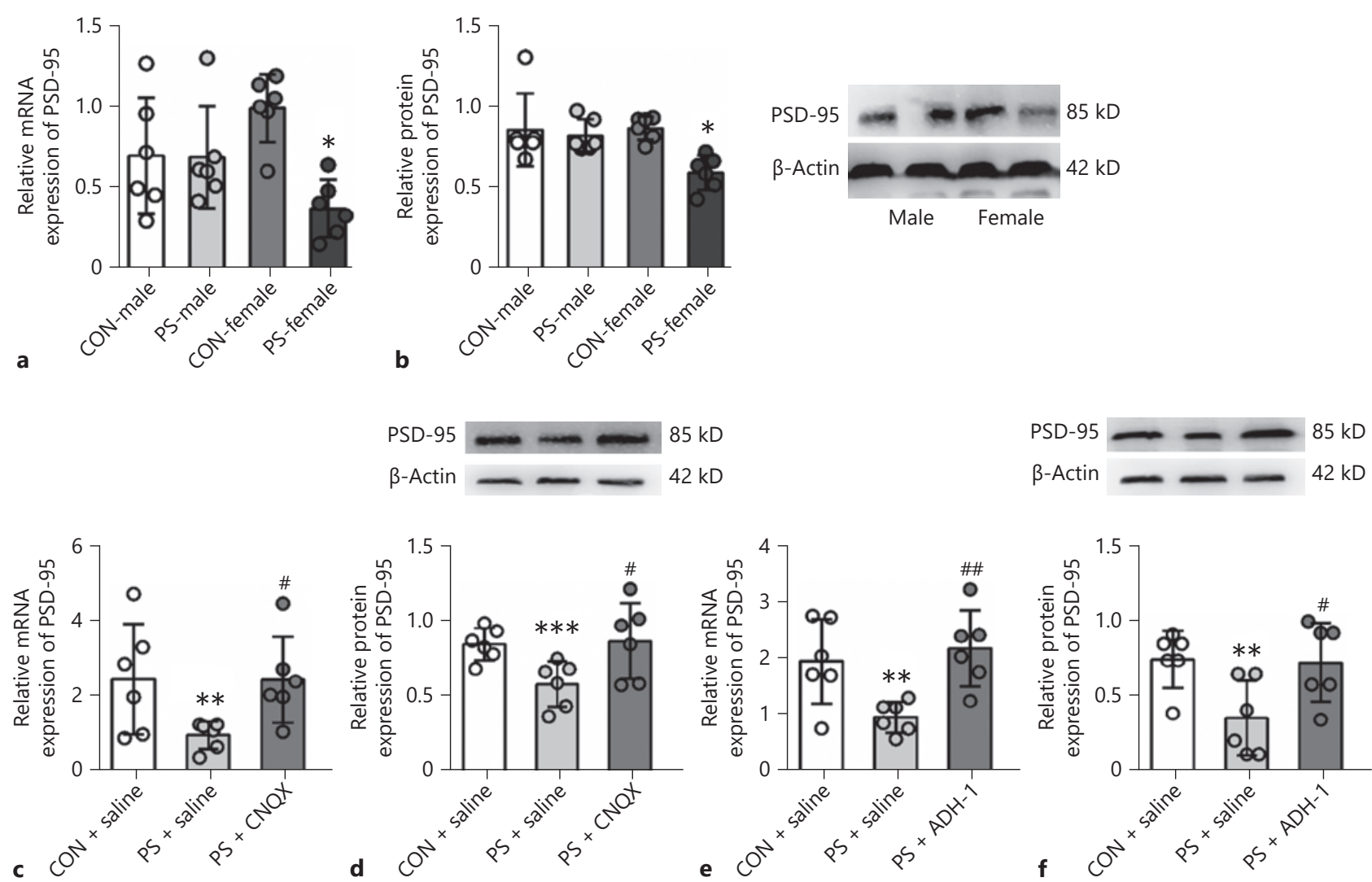

Fig. 7. The effects of PS, CNQX, and ADH-1 on PSD-95 expression. a, b Effects of PS on PSD-95 expression. c, $\mathbf{d}$ Effects of CNQX on PSD-95 expression. e, $\mathbf{f}$ Effects of ADH-1 on PSD-95 expression. * $p<0.05$ versus CONfemale, ${ }^{* *} p<0.05$ versus CON + saline, ${ }^{* * *} p<0.01$ versus CON + saline, ${ }^{\#} p<0.05$ versus PS + saline, ${ }^{\# \#} p<0.01$ versus $\mathrm{PS}+$ saline. PS, prenatal stress.

as the effect of PS $\left(F_{[1,20]}=97.783, p<0.001 ; F_{[1,20]}=\right.$ $19.100, p<0.001)$ and $\mathrm{ADH}-1$ administration $\left(F_{[1,20]}=\right.$ $\left.39.116, p<0.001 ; F_{[1,20]}=31.484, p<0.001\right)$. ADH-1 also reduced GluA1 expression in hippocampus of female offspring in both CON (GluA1 mRNA, $F_{[1,20]}=11.820$, $p=$ 0.006; GluA1 protein, $\left.F_{[1,20]}=7.892, p=0.018\right)$ and PS group (GluA1 mRNA, $F_{[1,20]}=27.328, p<0.001$; GluA1 protein, $F_{[1,20]}=24.144, p=0.001$, shown in Figure $\left.6 c, d\right)$. This indicated that the increase of GluAl may be due to the increase of N-cadherin caused by PS, which mediated depressive-like behavior in adolescent female offspring.

\section{Hippocampal Postsynaptic Density Mediates the}

Depressive-Like Behavior of Female Offspring

following PS

To elucidate the mechanism of GluA1-mediated depressive-like behavior of female offspring following PS, we performed an analysis of PSD-95 expression in the hippocampus. Based on the 2-way ANOVA, the interaction ( $\operatorname{sex} \times \mathrm{PS}$ ) on the relative $\mathrm{mRNA}$ and protein expression of PSD-95 $\left(F_{[1,20]}=7.375, p=0.013 ; F_{[1,20]}=4.488\right.$, $p=0.047)$ were observed, as well as the effect of PS $\left(F_{[1}\right.$, 20] $\left.=7.832, p=0.011 ; F_{[1,20]}=7.560, p=0.012\right)$. We found PS-induced depressive-like behavior in female offspring (shown in Fig. 2) by down-regulating PSD-95 (PSD-95 mRNA, $F_{[1,20]}=30.948, p<0.001$; PSD-95 protein, $F_{[1,20]}$ $=27.616, p<0.001$; shown in Figure 7a, b). Furthermore, CNQX significantly increased PSD-95 expression in the hippocampus in the female offspring after PS exposure (PSD-95 mRNA, $F_{[1,20]}=9.134, p=0.013$; PSD-95 protein, $F_{[1,20]}=5.676, p=0.038$; shown in Figure $7 c, d$ ). $\mathrm{ADH}-1$ also rescued the down-regulation of PSD-95 in PS female offspring (PSD-95 mRNA, $F_{[1,20]}=16.929, p=$ 0.002 ; PSD-95 protein, $F_{[1,20]}=6.239, p=0.032$, shown in 


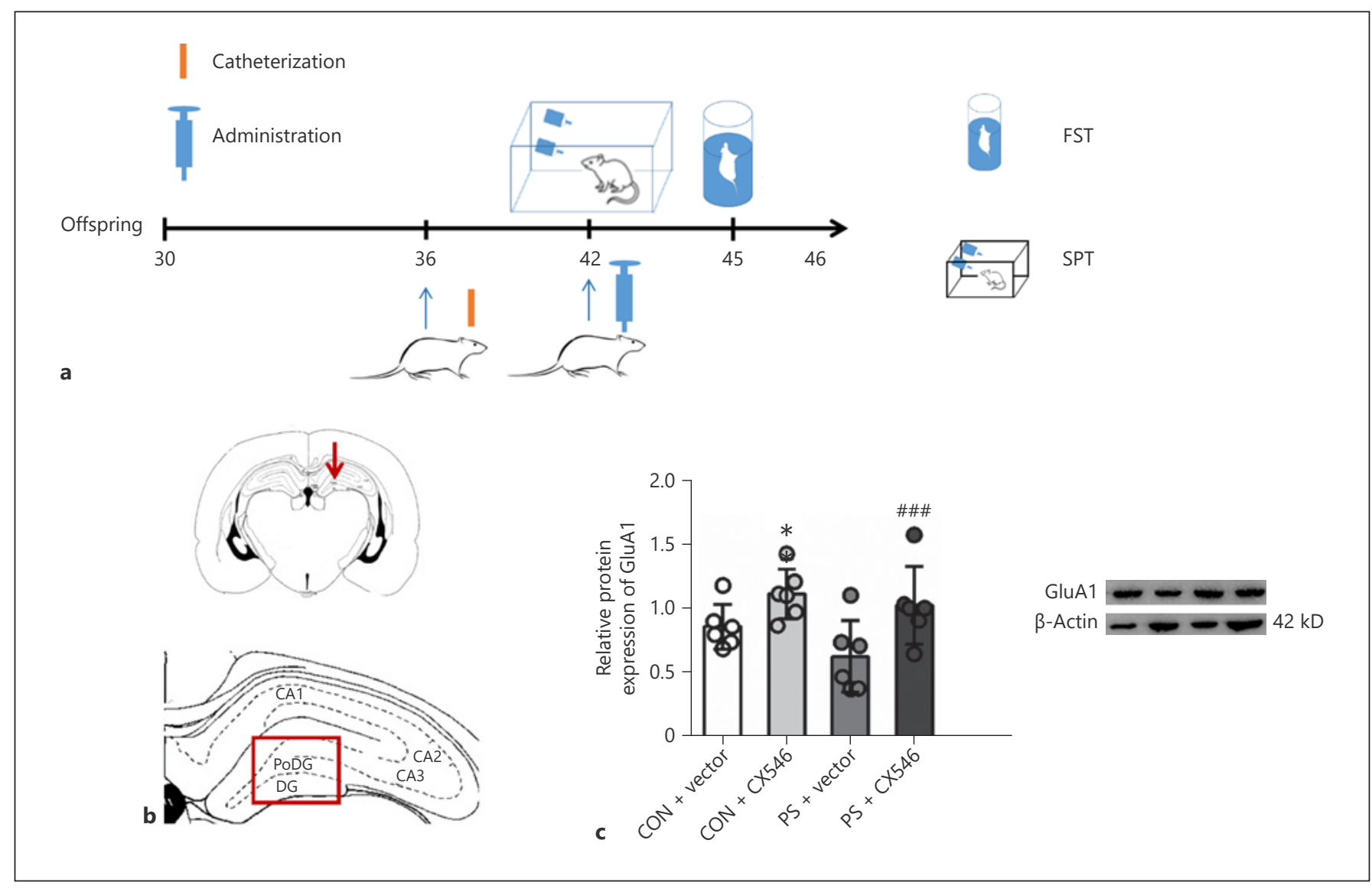

Fig. 8. Effects of CX546 administration in the dentate gyrus on the expression of GluA1. a Study design of PS model establishment, CX546 administration, and behavioral test. b Location of CX546 administration in the hippocampus. c Protein expression of GluA1 in the hippocampus. ${ }^{*} p<0.05$ versus $\mathrm{CON}+$ saline, ${ }^{\# \# \#} p<0.001$ versus PS + saline. PS, prenatal stress.

Figure 7e, f). These findings suggested that PS might increase expression of $\mathrm{N}$-cadherin, leading to upregulated expression of GluA1, especially in the dentate gyrus, and resulting in reduced levels of the postsynaptic protein PSD-95, which mediated depressive-like behavior in adolescent female offspring.

Upregulation of GluA1 in the Dentate Gyrus of the Hippocampus Is Sufficient to Induce Depressive-Like Behavior in PS Male Offspring in Response to CX546

\section{Administration}

To demonstrate that GluA1 mediates the gender-dependent depressive-like behavior in PS offspring, we first investigated the effect of CX546 administration by intraperitoneal injection on the depressive-like behavior of PS male offspring. We found that PS had no effect on the depressive-like behavior of male offspring. However, in- traperitoneal injection of CX546 upregulated the GluA1 expression in the hippocampus (online suppl. material 3, Fig. 3b) and induced the depressive-like behavior of PS male offspring (online suppl. material 3, Fig. 3d, f, g).

We further explored whether the upregulation of GluA1 in the dentate gyrus is sufficient to induce depressive-like behavior in PS male offspring in response to CX546 administration (shown in Fig. 8a, b). We observed the overall interaction $(\mathrm{CX} 546 \times$ PS) for the GluA1 expression $\left(F_{[1,20]}=5.265, p=0.033\right)$ and the effect of CX546 administration $\left(F_{[1,20]}=35.548 p<0.001\right)$. CX546 administration significantly increased the GluA1 expression in the dentate gyrus of male offspring, in both CON and PS group $\left(F_{[1,20]}=5.853, p=0.036 ; F_{[1,20]}=40.060 p<0.001\right.$, shown in Figure 8c). The results of immunofluorescence staining also showed that the GluAl expression significantly increased in the dentate gyrus of PS group follow- 


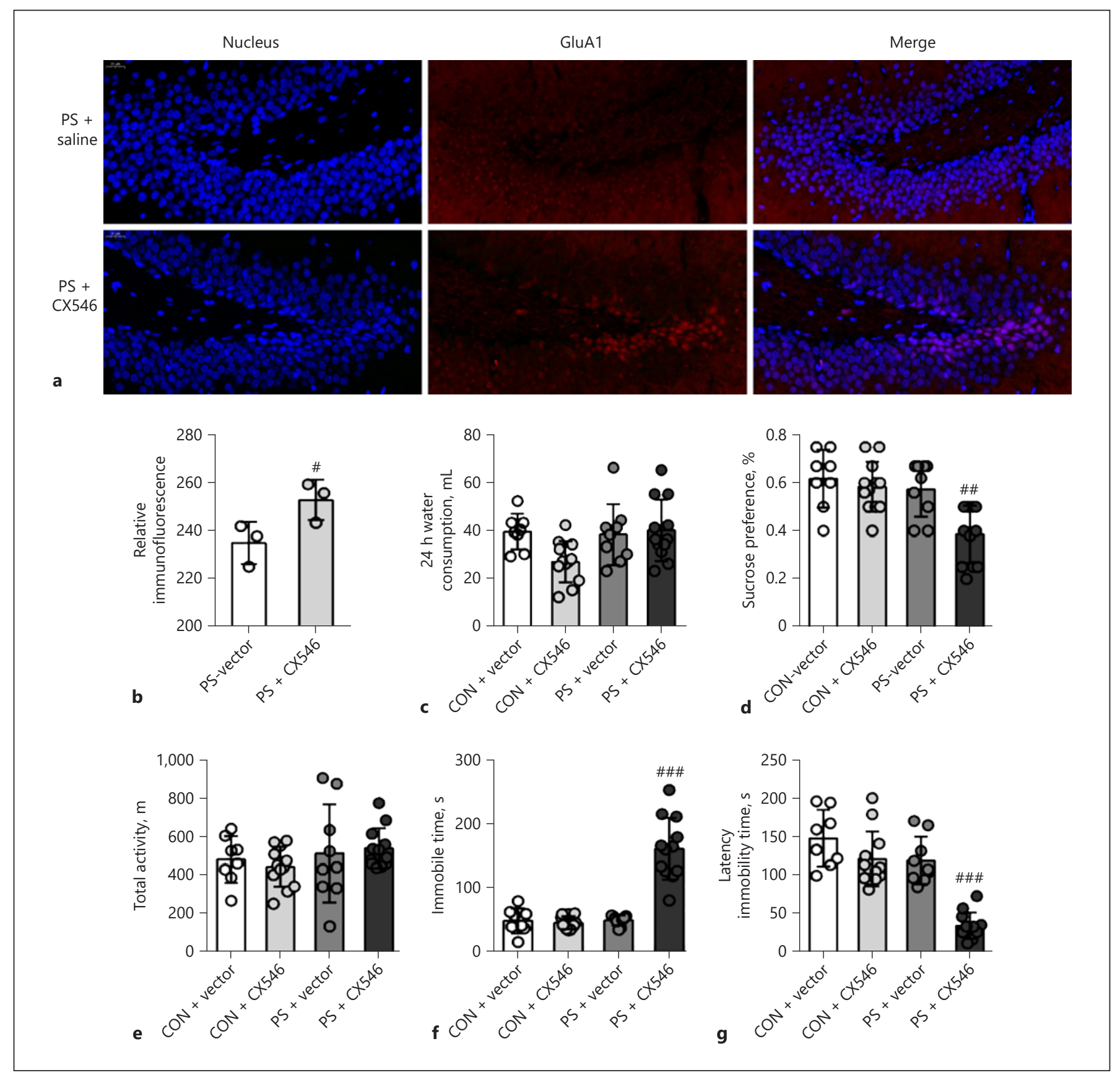

Fig. 9. Effects of CX546 administration in the hippocampus dentate gyrus on the expression of GluA1 and the behavior. a Representative images of immunofluorescence staining showing GluA1 in the dentate gyrus. $N=6-7$ mice/group, and the number of experiments $=3$. Magnification $\times 40$. Scale bar, $50 \mu \mathrm{m}$. b Immuno- fluorescence intensity analysis. c 24-h water consumption in the SPT. d Sucrose preference. e Total activity in the FST. $\mathbf{f}$ Immobility time in the FST. $\mathbf{g}$ Latent immobility time in the FST. ${ }^{\# \#} p<0.01$

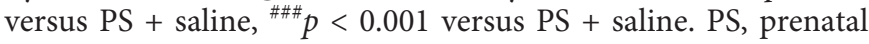
stress; SPT, sucrose preference test; FST, forced swim test. 
ing CX546 administration $\left(F_{[1,20]}=12.202, p=0.025\right.$, shown in Fig. 9a, b).

Moreover, the overall interaction $(\mathrm{CX} 546 \times \mathrm{PS})$ for the sucrose consumption, the immobility time, and the latent immobility time was observed $\left(F_{[1,41]}=4.412, p=0.043\right.$; $\left.F_{[1,41]}=40.138, p<0.001 ; F_{[1,41]}=8.940, p=0.005\right)$ based on the 2-way ANOVA. The behavioral testing showed that CX546 administration in the dentate gyrus had no effect on depressive-like behavior of male offspring in the CON group. However, the one-way ANOVA-stratified analysis showed that CX546 induced the depressive-like behavior in male offspring following PS. The sucrose consumption in the PS + CX546 group was significantly decreased $32.48 \%$ compared to that in the PS + vector group $\left(F_{[1,19]}=13.027, p=0.002\right.$, shown in Figure 9d). In the FST, the immobility time of the PS + CX546 group was longer than that of the PS + vector group $\left(F_{[1,19]}=46.128\right.$, $p<0.001$, shown in Figure 9f), and the latent immobility time was reduced after CX546 administration $\left(F_{[1,19]}=\right.$ $64.669, p<0.001$, shown in Figure 9g). These results further confirm that GluA1 was required for the depressivelike behavior in adolescent offspring after PS exposure.

\section{Discussion}

Numerous studies have shown that PS leads to depression in adolescent offspring $[2,3]$ with gender specificity [4]. Female offspring are more likely to develop emotional disorders, and sexually dimorphic responses to PS in offspring are 1 reason for the increased prevalence of depression among females [5]. In this study, we found that only female offspring showed depressive-like behavior during adolescence when the dams were exposed to restraint stress during the late stage of pregnancy, while male offspring were resistant, which is consistent with clinical research [5].

Although the role of AMPARs in depression has been mentioned before [40, 41], gender differences in AMPAR-mediated depressive-like behavior following PS are unclear. In this study, we found that PS only increased the expression of $\mathrm{N}$-cadherin in the dentate gyrus of female offspring, which in turn increased GluA1, mediating depressive-like behavior. However, expression of N-cadherin was not altered in the dentate gyrus of male offspring, and they did not exhibit depressive-like behavior in response to PS. The differential expression of N-cadherin-GluA1 in the dentate gyrus induced by PS in adolescent offspring is a key factor in mediating gender differences in depressive-like behavior.
There are different explanations for gender differences in depression. First, Salk et al. [1] found that gender differences in depression mainly emerge during adolescence, while there is no gender difference or even a somewhat higher prevalence of depression among boys than girls in childhood. In addition, observations in adulthood are inconsistent with the gender difference in depression. Furthermore, stress duration may mediate gender differences in depression. Studies have proved that females develop depressive-like behavior following shorter stress duration; on the other hand, males require longer durations of stress to develop depressive-like behavior [4244]. In addition, Muir et al. [45] found that after 4 days of chronic variable stress, females developed depressive-like behaviors, while it takes 21 days for males to develop these behaviors. Finally, differences in female and male sex hormones are also important for gender differences with respect to depression. Women are more likely to suffer from depression during periods of marked hormonal fluctuations, including adolescence, postpartum, and perimenopause periods [46]. Rodent studies have also shown that ovariectomized female rats exhibit depressive-like behavior $[47,48]$.

In our study, depressive-like behavior in adolescent female offspring might be due to prenatal restraint stress for 7 days, while this stress duration did not induce depressive-like behavior in male offspring. Moreover, estrogen fluctuations in adolescent female offspring may alter $\mathrm{N}$-cadherin expression in the dentate gyrus, which mediated GluA1-dependent depressive-like behavior in female offspring.

In our previous findings, PS decreased the expression of GluA1-3 in the hippocampus and induced depressive-like behavior in male offspring [32], which is inconsistent with the results of this study. The possible reasons are as follows. First, our previous study only focused on male offspring, while depressive-like behavior and AMPAR expression in female offspring were not evaluated. Second, adolescent offspring were observed in the present study, while previous results occurred in childhood (21 days after birth) in male offspring. In addition, Staples et al. [49] found that GluA1 expression decreased and GluA2 expression increased in the dentate gyrus of female adult offspring following PS. This difference may also be due to the different ages of the offspring.

The development of the rat hippocampus mainly occurs during the third trimester, which is also an active period of accelerated development of synapse formation. Therefore, stress during late pregnancy is more likely to 
cause an imbalance in hippocampal functions, leading to depression [50]. This is 1 of the important reasons that we selected the hippocampus for analysis. In this study, we also found that the effects of PS on N-cadherin and GluA1 mainly occurred in the dentate gyrus, and N-cadherin and GluA1 were co-localized. These findings suggested that N-cadherin regulated GluA1 in the dentate gyrus, mediating depressive-like behavior in adolescent female offspring following PS.

Studies have confirmed that AMPARs regulate synaptic plasticity in the hippocampus. Our previous study shows that the dendrites at the top of pyramidal neurons were shorter, the dendrite fulcrum was decreased, and expression of syn-1 was decreased in the hippocampus of the offspring exposed to PS [9]. This suggests that the altered synaptic plasticity in the hippocampus might be important for depressive-like behavior following PS. PSD95 is critical for AMPAR-dependent synaptic plasticity [51]. We analyzed its expression in the hippocampus of female offspring with depressive-like behavior. We found that the expression of PSD-95 was decreased in the hippocampus of PS female offspring with depressive-like behavior. Furthermore, systemic administration of AMPAR antagonists rescued the depressive-like behavior and PSD-95 expression. This further confirmed that PS caused the upregulation of GluA1 expression in the dentate gyrus of female offspring, affecting synaptic plasticity by reducing PSD-95, which mediated the depressive-like behavior in adolescent female offspring.

$\mathrm{ADH}-1$ is a cyclic pentapeptide that disrupts $\mathrm{N}$-cadherin interactions and has been shown to inhibit cell growth and tumor progression both in vitro and in vivo [52]. In our study, we found an antidepressant effect of ADH-1, wherein intraperitoneal $\mathrm{ADH}-1$ resulted in a significant reduction in N-cadherin and GluAl in the dentate gyrus, improving depressive-like behavior in female offspring induced by PS. Notably, this is the first study to target $\mathrm{N}$-cadherin as a potential therapeutic modality in depression.

The present study has limitations. First, direct evidence that upregulated $\mathrm{N}$-cadherin-GluA1 in the dentate gyrus induced depressive-like behavior in PS adolescent female rat offspring is lacking. Second, we did not examine the AMPAR and N-cadherin expressions in the control group treated with CNQX and ADH-1. Third, to conclude that "hippocampal postsynaptic density mediates the depressive-like behavior of female offspring following PS," we should analyze the levels of PSD-95 not only in total lysates but also in PSD-enriched preparations.

In conclusion, our study found that the high incidence rate of depression in adolescent women probably results from the susceptibility of female offspring to PS. We further elucidated that PS increased expression of $\mathrm{N}$-cadherin, which upregulated GluA1 expression in the dentate gyrus, mediating depressive-like behavior in adolescent female offspring by reducing PSD-95. We also found that $\mathrm{ADH}-1$, an antagonist of N-cadherin, exerted potential antidepressant effects. This study provides insight for elucidating the underlying mechanisms of adolescent female depression and antidepressant drugs.

\section{Acknowledgments}

We sincerely thank the Key Laboratory of environment and disease-related genes of Ministry of Education of Xi'an Jiaotong University for their support in this study.

\section{Statement of Ethics}

All studies involving animals have been approved by the Institutional Animal Care and Use Committee of Xi'an Jiaotong University (No. 2018012) and followed the ARRIVE guidelines.

\section{Conflict of Interest Statement}

The authors have no conflicts of interest to declare.

\section{Funding Sources}

This work was supported by the National Natural Science Foundation of China (No. 81873805).

\section{Author Contributions}

Shao Shuya proposed the idea of the research. Shuya Shao, Hui $\mathrm{Li}$, and Zhongliang Zhu designed the study. Shuya Shao performed behavioral and molecular biological experiments, analyzed data, and wrote and revised the manuscript, during which Yufang Si helped a lot. Dan Yao, Senya Li, and Jing Li managed some behavioral experiments. Huiping Zhang undertook some PS model experiments. Corresponding authors Hui Li also supervised the study, acquired the funding, and revised the manuscript.

\section{Data Availability Statement}

All data generated or analyzed during this study are included in this article and its online suppl. material. Further enquiries can be directed to the corresponding author. 


\section{References}

1 Salk RH, Hyde JS, Abramson LY. Gender differences in depression in representative national samples: meta-analyses of diagnoses and symptoms. Psychol Bull. 2017;143:783822.

2 Betts KS, Williams GM, Najman JM, Alati R. Maternal depressive, anxious, and stress symptoms during pregnancy predict internalizing problems in adolescence. Depress Anxiety. 2014;31:9-18.

3 Maxwell SD, Fineberg AM, Drabick DA, Murphy SK, Ellman LM. Maternal prenatal stress and other developmental risk factors for adolescent depression: spotlight on sex differences. J Abnorm Child Psychol. 2018; 46:381-97.

4 Agnafors S, Sydsjö G, Comasco E, Bladh M, Oreland L, Svedin CG. Early predictors of behavioural problems in pre-schoolers: a longitudinal study of constitutional and environmental main and interaction effects. BMC Pediatr. 2016;16:76.

5 Hicks LM, Swales DA, Garcia SE, Driver C, Davis EP. Does prenatal maternal distress contribute to sex differences in child psychopathology? Curr Psychiatry Rep. 2019;21:7.

6 Jia N, Li Q, Sun H, Song Q, Tang G, Sun Q, et al. Alterations of Group I mGluRs and BDNF associated with behavioral abnormity in prenatally stressed offspring rats. Neurochem Res. 2015;40:1074-82.

7 Su Q, Zhang H, Dang S, Yao D, Shao S, Zhu Z, et al. Hippocampal protein kinase c gamma signaling mediates the impairment of spatial learning and memory in prenatally stressed offspring rats. Neuroscience. 2019;414:186-99.

8 Van den Hove DL, Kenis G, Brass A, Opstelten R, Rutten BP, Bruschettini M, et al. Vulnerability versus resilience to prenatal stress in male and female rats; implications from gene expression profiles in the hippocampus and frontal cortex. Eur Neuropsychopharmacol. 2013;23:1226-46.

9 Priest AV, Shafraz O, Sivasankar S. Biophysical basis of cadherin mediated cell-cell adhesion. Exp Cell Res. 2017;358:10-3.

10 Alimperti S, Andreadis ST. $\mathrm{CDH} 2$ and $\mathrm{CDH} 11$ act as regulators of stem cell fate decisions. Stem Cell Res. 2015;14:270-82.

11 Taneyhill LA, Schiffmacher AT. Should I stay or should I go? Cadherin function and regulation in the neural crest. Genesis. 2017;55:55.

12 Schaarschuch A, Hertel N. Expression profile of $\mathrm{N}$-cadherin and protocadherin-19 in postnatal mouse limbic structures. J Comp Neurol. 2017;26(4):663-80.

13 Beneyto M, Meador-Woodruff JH. Expression of transcripts encoding AMPA receptor subunits and associated postsynaptic proteins in the macaque brain. J Comp Neurol. 2004; 468:530-54

14 Tanaka H, Shan W, Phillips GR, Arndt K, Bozdagi O, Shapiro L, et al. Molecular modification of $\mathrm{N}$-cadherin in response to synaptic activity. Neuron. 2000;25:93-107.
15 Bozdagi O, Wang XB, Nikitczuk JS, Anderson TR, Bloss EB, Radice GL, et al. Persistence of coordinated long-term potentiation and dendritic spine enlargement at mature hippocampal CA1 synapses requires $\mathrm{N}$-cadherin. J Neurosci. 2010;30:9984-9.

16 Mendez P, De Roo M, Poglia L, Klauser P, Muller D. N-cadherin mediates plasticity-induced long-term spine stabilization. J Cell Biol. 2010;189:589-600.

17 Brigidi GS, Sun Y, Beccano-Kelly D, Pitman K, Mobasser M, Borgland SL, et al. Palmitoylation of $\delta$-catenin by DHHC5 mediates activity-induced synapse plasticity. Nature neuroscience. 2014;17:522-32.

18 Tai CY, Mysore SP, Chiu C, Schuman EM. Activity-regulated $\mathrm{N}$-cadherin endocytosis. Neuron. 2007;54:771.

19 Nuriya M, Huganir RL. Regulation of AMPA receptor trafficking by N-cadherin. J Neurochem. 2006;97:652-61.

20 Gross M, Sheinin A, Nesher E, Tikhonov T, Baranes D, Pinhasov A, et al. Early onset of cognitive impairment is associated with altered synaptic plasticity and enhanced hippocampal GluA1 expression in a mouse model of depression. Neurobiol Aging. 2015;36: 1938-52.

21 Zhang H, Etherington LA, Hafner AS, Belelli D, Coussen F, Delagrange P, et al. Regulation of AMPA receptor surface trafficking and synaptic plasticity by a cognitive enhancer and antidepressant molecule. Mol Psychiatry. 2013;18:471-84.

22 Zhang H, Bramham CR. Bidirectional dysregulation of AMPA receptor-mediated synaptic transmission and plasticity in brain disorders. Front Synaptic Neurosci. 2020;12:26.

23 Dore K, Malinow R. Elevated PSD-95 blocks ion-flux independent LTD: a potential new role for PSD-95 in synaptic plasticity. Neuroscience. 2020;456:43-9.

24 Arcego DM, Toniazzo AP, Krolow R, Lampert C, Berlitz C, Dos Santos Garcia E, et al. Impact of high-fat diet and early stress on depressive-like behavior and hippocampal plasticity in adult male rats. Mol Neurobiol. 2018; 55:2740-53

25 Zhang RX, Han Y, Chen C, Xu LZ, Li JL, Chen $\mathrm{N}$, et al. EphB2 in the medial prefrontal cortex regulates vulnerability to stress. Neuropsychopharmacology. 2016;19(Suppl_1):73-4.

26 Cai Q, Zhu Z, Huang S, Li H, Fan X, Jia N, et al. Sex and region difference of the expression of ERK in prenatal stress offspring hippocampus. Int J Dev Neurosci. 2007;25:207-13.

27 Lu Y, Zhang J, Zhang L, Dang S, Su Q, Zhang $\mathrm{H}$, et al. Hippocampal acetylation may improve prenatal-stress-induced depressionlike behavior of male offspring rats through regulating AMPARs expression. Neurochem Res. 2017;42:3456-64.
28 Morley-Fletcher S, Zuena AR, Mairesse J, Gatta E, Van Camp G, Bouwalerh H, et al. The reduction in glutamate release is predictive of cognitive and emotional alterations that are corrected by the positive modulator of AMPA receptors $S 47445$ in perinatal stressed rats. Neuropharmacology. 2018;135:284-96.

29 Zhang XH, Jia N, Zhao XY, Tang GK, Guan LX, Wang D, et al. Involvement of pGluR1, EAAT2 and EAAT3 in offspring depression induced by prenatal stress. Neuroscience. 2013;250:333-41.

30 Maccari S, Piazza PV, Kabbaj M, Barbazanges A, Simon H, Le Moal M. Adoption reverses the long-term impairment in glucocorticoid feedback induced by prenatal stress. J Neurosci. 1995;15:110-6.

31 Koehl M, Darnaudéry M, Dulluc J, Van Reeth O, Le Moal M, Maccari S. Prenatal stress alters circadian activity of hypothalamo-pituitaryadrenal axis and hippocampal corticosteroid receptors in adult rats of both gender. J Neurobiol. 1999;40:302-15.

32 Lu Y, Zhang J, Zhang L, Dang S, Su Q, Zhang $\mathrm{H}$, et al. Hippocampal acetylation may improve prenatal-stress-induced depressionlike behavior of male offspring rats through regulating AMPARs expression. Neurochem Res. 2017;42:3456-64.

33 Becker G, Kowall M. Crucial role of the postnatal maternal environment in the expression of prenatal stress effects in the male rats. J Comp Physiol Psychol. 1977;91:1432-46.

34 Bäckström P, Hyytiä P. Attenuation of cocaine-seeking behaviour by the AMPA/kainate receptor antagonist CNQX in rats. Psychopharmacology. 2003;166:69-76.

35 Li H, Price DK, Figg WD. ADH1, an N-cadherin inhibitor, evaluated in preclinical models of angiogenesis and androgen-independent prostate cancer. Anticancer Drugs. 2007; 18:563-8.

36 Zhou W, Wang N, Yang C, Li XM, Zhou ZQ, Yang JJ. Ketamine-induced antidepressant effects are associated with AMPA receptorsmediated upregulation of $\mathrm{mTOR}$ and BDNF in rat hippocampus and prefrontal cortex. Eur Psychiatry. 2014;29:419-23.

37 Paxinos G, Watson C. The rat brain in stereotaxic coordinates. 6th ed.

38 Porsolt RD, Anton G, Blavet N, Jalfre M. Behavioural despair in rats: a new model sensitive to antidepressant treatments. Eur J Pharmacol. 1978;47:379-91.

39 Korenbrot CC, Huhtaniemi IT, Weiner RI Preputial separation as an external sign of pubertal development in the male rat. Biol Reprod. 1977;17:298-303.

40 Zhang RX, Han Y, Chen C, Xu LZ, Li JL, Chen $\mathrm{N}$, et al. EphB2 in the medial prefrontal cortex regulates vulnerability to stress. Neuropsychopharmacology. 2016;41:2541-56. 
41 Martínez-Rivera A, Hao J, Tropea TF, Giordano TP, Kosovsky M, Rice RC, et al. Enhancing VTA Ca(v)1.3 L-type $\mathrm{Ca}(2+)$ channel activity promotes cocaine and mood-related behaviors via overlapping AMPA receptor mechanisms in the nucleus accumbens. Molecular Psychiatry. 2017;22:1735-45.

42 Hodes GE, Pfau ML, Purushothaman I, Ahn HF, Golden SA, Christoffel DJ, et al. Sex differences in nucleus accumbens transcriptome profiles associated with susceptibility versus resilience to subchronic variable stress. J Neurosci. 2015;35:16362-76.

43 Lorsch ZS, Loh YE, Purushothaman I, Walker DM, Parise EM, Salery M, et al. Estrogen receptor a drives pro-resilient transcription in mouse models of depression. Nat Commun. 2018;9:1116.

44 Labonté B, Engmann O, Purushothaman I, Menard C, Wang J, Tan C, et al. Sex-specific transcriptional signatures in human depression. Nat Med. 2017;23:1102-11.

45 Muir J, Tse YC, Iyer ES, Biris J, Cvetkovska V, Lopez J, et al. Ventral Hippocampal afferents to nucleus accumbens encode both latent vulnerability and stress-induced susceptibility. Biological Psychiatry. 2020;88(11): 843-54.

46 Solomon MB, Herman JP. Sex differences in psychopathology: of gonads, adrenals and mental illness. Physiol Behav. 2009;97:250-8.

47 Tantipongpiradet A, Monthakantirat $\mathrm{O}$, Vipatpakpaiboon O, Khampukdee C, Umehara K, Noguchi H, et al. Effects of puerarin on the ovariectomy-induced depressive-like behavior in ICR mice and its possible mechanism of action. Molecules. 2019;24:24.

48 Eid RS, Lieblich SE, Duarte-Guterman P, Chaiton JA, Mah AG, Wong SJ, et al. Selective activation of estrogen receptors $\alpha$ and $\beta$ : im- plications for depressive-like phenotypes in female mice exposed to chronic unpredictable stress. Horm Behav. 2020;119:104651.

49 Staples MC, Porch MW, Savage DD. Impact of combined prenatal ethanol and prenatal stress exposures on markers of activity-dependent synaptic plasticity in rat dentate gyrus. Alcohol. 2014;48:523-32.

50 Udagawa J, Hino K. Impact of maternal stress in pregnancy on brain function of the offspring. Nihon Eiseigaku Zasshi. 2016;71:18894.

51 Bhattacharyya S, Biou V, Xu W, Schlüter O, Malenka RC. A critical role for PSD-95/ AKAP interactions in endocytosis of synaptic AMPA receptors. Nat Neurosci. 2009;12: 172-81.

52 Blaschuk OW. N-cadherin antagonists as oncology therapeutics. Philos Trans R Soc Lond B Biol Sci. 2015;370:20140039. 